been devised; the effect of the IBP has been to change the emphasis of some research projects, and hopefully to co-ordinate them on a world scale.

In Britain this activity is being supported from a number of sources; the Royal Society has supplied $£ 34,000$ for the past two years, and this year the figure has been more than doubled. This money comes through the Department of Education and Science, and is earmarked for the IBP; the Natural Environment Research Council also gets money for specific IBP projects from the Treasury, but the other research councils find it out of their normal income.

\section{British Association Meeting}

THe British Association for the Advancement of Science will meet this year in Leeds, from August 30 to September 6 . The preliminary programme, just published, shows that the meeting will be as wide, varied and probably as indigestible as ever. There will be six symposia; two are likely to appeal to hardened veterans-The Planning and Financing of Research and Development in the United Kingdom, and Why Choose Science? Factors Affecting the Choice of Subjects at School and University. The others are brighter and more general-Britain in A.D. 2000, The Control of Crime, Escape into Space ? and Our Crowded World. The titles convey accurately what the symposia will be about, and the one on space research at least looks likely to produce argument. Lord Bowden will be there putting his well rehearsed arguments against space research, and with luck will be opposed by a distinguished American scientist concerned with the U.S. space effort, as yet unnamed.

There will, in addition, be the usual sectional programmes, which for the first time are given in considerable detail in the preliminary programme. These cover the whole range of science, and include discussions of the sociology of science, and, inevitably, the science of science.

\section{EMBO Moves On}

THE European Molecular Biology Organization seems to have won the sympathies if not yet the tangible support of a great many European governments. At a meeting called earlier this month by the Swiss Government at the CERN laboratory in Geneva, official delegations from eleven countries were broadly sympathetic towards the proposal that public funds should be used to support the work of EMBO when its present funds are exhausted some time next year. A further conference is to be held towards the end of 1967, when it is expected that governments will be prepared to translate their expressions of goodwill into money.

So far EMBO, which is constitutionally a private organization with 160 individual members, has been supported largely by the Volkswagen Foundation. It was formed four years ago on the model of CERN with the intention of fostering European activities in molecular biology. So far the organization has been largely concerned with organizing and financing exchanges of people between European laboratories, and several hundreds of visits, usually for periods of a few months, have already been made. From the beginning, the organization has had in mind a project to create a European laboratory for molecular biology, and one of the surprises of the conference at CERN this month was that the French delegation announced that the French Government would actually provide a site for a laboratory in France if funds for building and operation could be found. Not all delegations were as enthusiastic, although only the Belgians were openly sceptical.

Although it is, of course, too soon to know how EMBO will make the transition from being a private organization to a publicly supported consortium, the chances are high that governments will agree to provide support for a continuing programme of exchanges, possibly on a larger scale. The laboratory is clearly a more tricky matter. Some governments are understood to have taken the view at Geneva that the urgent need is to strengthen the European centres which already exist and not to create new ones to act as magnets for skilled people. Within EMBO, and particularly among those members from countries in which molecular biology is still a Cinderella, the laboratory is thought to be an essential means of keeping European scientists in Europe.

\section{Masters and Slaves}

\section{from a Correspondent in Cell Biology}

THE organization of chromosomes remains one of the enigmas of cell biology. Two interesting new models of chromosome organization have recently been published by Callan ( $J$. Cell Sci., 2, I; 1967) and Whitehouse (ibid., page 9 ).

Callan's proposal is that in each chromosome there may be several copies of the same gene arranged as serially repeated sequences of nucleotides in a single DNA molecule. This serves in particular to explain his own observations of lampbrush chromosomes of amphibian oocytes and Keyl's data on the DNA content of bands in chironomus salivary gland chromosomes. In Callan's model, either the first or the last gene in such a sequence acts as a "master", simply by virtue of its terminal position: the other genes are the "slaves". Recombination is restricted to master genes, and once during the life cycle, after recombination has occurred between chromatids of homologous chromosomes at meiosis, the nucleotide sequences of both nucleotide chains of the slave genes are matched and if necessary corrected with respect to those of the master gene. Finally, only slave genes are used as templates for the synthesis of RNA.

If recombination is restricted to master genes, one of the consequences of Callan's model is that neighbouring master genes are separated from each other by a series of slaves. This cannot be reconciled with data Whitehouse has obtained in studies of recombination in Aspergillus nidulans, for these imply that only one copy of each gene is present and that each gene must be in contact with its neighbours. This interpretation of the recombination studies can be reconciled with the inference that lampbrush chromosomes carry several copies of the same gene by modifying Callan's model.

To this end, Whitehouse suggests that slave genes are removed from a chromatid before interchromatid recombination at meiosis by intrachromatid recombination between the first (master) and the last (slave) genes in a repeated sequence. This results in a closed 